\title{
Trabalho docente, feminização e pandemia
}

\author{
The work of teaching, feminization, and pandemic
}

\author{
Trabajo docente, feminización y pandemia
}

\author{
SÂMARA CARLA LOPES GUERRA DE ARAUJO* \\ Secretaria Municipal de Educação de Belo Horizonte, Belo Horizonte-MG, Brasil.
}

\section{SILVIA CRISTINA YANNOULAS}

Universidade de Brasília, Brasília-DF, Brasil.

\begin{abstract}
RESUMO:O texto aborda os efeitos da pandemia de Covid19 no trabalho docente realizado na educação básica brasileira, tendo em vista a especificidade de gênero. Contexto no qual as mulheres foram desafiadas a se reinventar. Discutimos o trabalho docente e a feminização durante o atual momento, recuperando conceitos caros aos estudos de gênero. Para tanto, foram analisados os dados produzidos em 2020 pela pesquisa realizada pelo Gestrado/UFMG, em parceria com a CNTE. Pesquisa esta que demonstrou a agudização dos problemas de gênero, imperantes antes da instauração do vírus.

Palavras-chave: Trabalho docente na pandemia. Educação básica. Divisão sexual do trabalho.
\end{abstract}

\begin{abstract}
The text addresses the effects of the Covid19 pandemic on the the work of teaching carried out in Brazilian basic education, with a view to gender specificity. Context in which women were challenged to reinvent themselves. We discussed the work of teaching, and feminization during the current moment, recovering concepts that are
\end{abstract}

* Pedagoga e Doutora em Educação pela Universidade Federal de Minas Gerais. Atua como professora na educação básica pública e no ensino superior privado. É pesquisadora do GESTRADO. E-mail: <asamaracarla@gmail.com>.

** Doutora em Sociologia pelo programa conjunto FLACSO/Sede Acadêmica Brasil e Universidade de Brasília. Pós-Doutora pela Faculdade de Educação da Universidade Federal de Minas Gerais. Professora da Universidade de Brasília e líder do Grupo de Pesquisa Trabalho, Educação e Discriminação (TEDis). E-mail: <silviayannoulas@unb.br>. 
substantial to gender studies. To this end, the data produced in 2020 by the research carried out by the Gestrado/UFMG, in partnership with CNTE, were analyzed. Research that demonstrated the worsening of gender problems, prevailing before the onset of the virus.

Keywords: The work of teaching in the pandemic. Basic education. Division of labour by gender.

RESUMEN: El texto aborda los efectos de la pandemia de Covid-19 en la labor docente realizada en la educación básica brasileña, teniendo en cuenta la especificidad de género, contexto en el que las mujeres fueron desafiadas a reinventarse. Discutimos el trabajo docente y la feminización en el momento actual, recuperando conceptos valiosos para los estudios de género. Para ello, los datos producidos en 2020 fueron analizados por la investigación realizada por el Gestrado/UFMG, en conjunto con CNTE, una investigación que demostró el agravamiento de los problemas de género, imperantes antes de la aparición del virus.

Palabras clave: Trabajo docente en la pandemia. Educación básica. División del trabajo en función del género

\section{Introdução}

A s desigualdades sociais entremeadas nas relações de classe, de gênero e étnicoraciais, que estruturam consubstancialmente as sociedades latino-americanas, ficaram escancaradas pelo contexto de uma pandemia causada pelo novo coronavírus (SARS-CoV-2) e a doença causada por ele (Covid-19). Sem igual na história, a pandemia afetou todos os países, criando a maior política de isolamento social conhecida e reconfigurando as sociedades. De maneira avassaladora, as desigualdades ficaram em evidência no acesso e usufruto de diversos direitos sociais constitucionalmente instituídos no Brasil, em 1988 (BRASIL, 1988): sanitário, econômico, político, cultural, educacional, tecnológico, entre outros.

Em relação ao contexto educacional, a pandemia da Covid-19 trouxe impactos em todo o mundo, o que não foi diferente para as escolas brasileiras. Tal situação significou o fechamento de instituições de ensino ${ }^{1}$ e a impossibilidade da frequência presencial às aulas, pelas(os) alunas(os), de todos os níveis e modalidades educacionais ${ }^{2}$. Professoras ${ }^{3} \mathrm{e}$ demais trabalhadoras da educação $0^{4}$ também não puderam acessar os espaços escolares e, em sua maioria, elas passaram a realizar aulas e atividades pedagógicas não presenciais.

Abordamos, neste texto, uma das especificidades dos efeitos da pandemia: como sempre, e talvez mais que sempre, a maior parte dos custos e efeitos negativos do contexto 
crítico foi social, cultural e politicamente atribuído às mulheres. Seja em razão do papel de cuidadoras na divisão sexual do trabalho (com a atual sobrecarga e intensificação das tarefas domésticas, sem apoio das redes ou das instituições, como creches e escolas), seja por sua presença massiva em atividades econômicas e profissões tidas socialmente como "feminizadas", como são aquelas das áreas da saúde, da educação, da administração pública, entre outras, as mulheres foram desafiadas a se reinventar na batalha contra a pandemia do vírus SARS-CoV-2, nos mais diversos âmbitos (particular; familiar; social; profissional, entre outros). Destacamos aquelas engajadas em profissões na área da saúde ou no ensino/trabalho remoto da educação e da administração pública.

Por isso, pretendemos discutir o trabalho docente na educação básica e a feminização na pandemia. Para tanto, o artigo está estruturado em três partes. Primeiro, é proposta uma reflexão teórica sobre o impacto da pandemia para as mulheres, recuperando conceitos caros dos estudos de gênero, à luz das atuais condições. Em seguida, a apresentação dos dados, desagregados por gênero, da pesquisa (GESTRADO, 2020a, 2020b), a qual foi realizada, em 2020, pelo Grupo de Estudos sobre Política Educacional e Trabalho Docente da Universidade Federal de Minas Gerais (Gestrado/UFMG), em parceria com a Confederação Nacional dos Trabalhadores em Educação (CNTE). Em terceiro lugar, discutimos os resultados, à luz do referencial teórico, para finalmente apresentar as considerações finais.

\section{Feminização na/da pandemia}

A literatura especializada aponta para os efeitos ambíguos dos processos de feminização de diversos aspectos da vida social, expressando simultaneamente elementos de resistência e de submissão à divisão sexual do trabalho historicamente constituída. Se, de um lado, os processos de feminização possibilitaram a incorporação das mulheres ao espaço público, à educação em todos os níveis e modalidades, ao emprego e à sua emancipação econômica, de outro, esses processos aconteceram junto com a racionalização do processo de trabalho em um contexto de profundas mudanças tecnológicas - nas relações de trabalho e nos mercados de trabalho - levando a uma acentuada precarização e intensificação, e somando-se à sobrecarga de trabalho decorrente da sua dupla presença (no espaço público e no doméstico) ${ }^{5}$.

Interessante registrar aqui que as profissões ditas "femininas", com forte conotação moralista e higienista no século XIX (magistério, enfermagem, serviço social), foram e, por vezes, ainda são consideradas semiprofissões ou "profissões subalternas" pela sociologia do trabalho da década de 50 do século passado. Todas elas estão vinculadas intrinsecamente ao cuidado de outros seres humanos (YANNOULAS, 2013) ${ }^{6}$.

Na pandemia, resulta muito difícil ignorar os aspectos negativos predominantes da feminização de certos trabalhos, ocupações e profissões. Os cuidados, profissionais ou não, foram desafiados intensamente, e colocados mais uma vez sob a responsabilidade 
das mulheres. Seja por lacuna ou por déficit histórico das políticas públicas, na pandemia, o Estado está mais ausente ainda com relação à sua responsabilidade com os direitos sociais, assumindo deliberadamente uma posição subsidiária, na melhor das hipóteses, mas predominantemente omissa.

Independente da classe social ou da qualidade da inserção das mulheres no mercado de trabalho, a família reafirmou-se, no paradigma da nova direita, que combina habilmente neoliberalismo e neoconservadorismo como instituição central e articuladora das demais instituições e arranjos das práticas sociais de cuidado. A sobrecarga sofrida pelas mulheres, especialmente aquelas que não podem fugir aos arranjos de cuidado predominantes, determina sua diferenciação de acesso e permanência no mercado de trabalho, tornando-as vulneráveis às diversas formas de precarização, haja vista a necessidade de se combinar a jornada de trabalho dentro e fora do âmbito doméstico (MARCONDES; YANNOULAS, 2012).

No contexto da pandemia da COVID-19, assim declarada pela Organização Mundial de Saúde (OMS), em março de $2020^{7}$ essas jornadas se sobrepuseram e agudizaram não apenas porque não havia condições de contar com a mínima corresponsabilidade do Estado ou com o apoio de redes familiares ou de vizinhança mas também pelo histórico existente, como dito aqui. Se já apontamos anteriormente a existência de múltiplas jornadas e da feminização dos cuidados (de crianças; pessoas com necessidades especiais; idosos, entre outros), nos últimos anos, surgiram duas questões inéditas na esteira da precarização e intensificação do trabalho das mulheres: a) as mulheres com idades entre 30 e 60 anos assumiram concomitantemente os cuidados de crianças e de idosos, como nunca antes, em razão do adiamento da maternidade entre as novas gerações e da longevidade da vida humana na atualidade, o que resultou em uma situação inédita de sobrecarga e intensificação de trabalho, com tarefas de cuidados no espaço privado; b) o contexto atual de pandemia, sendo o isolamento social a principal política pública de contenção da expansão dos casos e das mortes provocadas pelo Covid-19, a qual foi fomentada em todo o mundo, entre outras razões, pela não existência de uma vacina. A permanência de todos os membros da família em casa não significou divisão das tarefas domésticas entre todos.

As organizações feministas Sempreviva (SOF) e Gênero e Número, entre abril e maio de 2020, realizaram um interessante estudo sobre feminização e cuidados, junto a 2.641 mulheres de todas as regiões do Brasil, que demonstrou claramente a importância das questões em pauta. O trabalho das mulheres é um trabalho incessante e, durante a pandemia, esta situação e sensação atrelada foram agudizadas: "A economia só funciona porque o trabalho das mulheres, quase sempre invisibilizado e precarizado, não pode parar", como considera uma das respondentes do estudo. O estudo mostrou que $50 \%$ das mulheres entrevistadas passaram a cuidar de outra pessoa durante a pandemia, maioritariamente sozinhas, sendo mais significativa esta situação entre as mulheres 
rurais e negras. Mesmo com um leve aumento da participação de outras pessoas do núcleo familiar nas tarefas de cuidado apontado por algumas entrevistadas, a maioria das respondentes indicou que houve diminuição do envolvimento de outras pessoas no cuidar e que esta participação é vista apenas como "colaboração", sem o mesmo nível de intensidade e responsabilidade. Para as que continuam trabalhando, a situação de distanciamento social é ainda mais angustiante, pois não deixam de realizar tarefas domésticas e, não raras vezes, seus rendimentos são o único sustento da casa. Exaustão é a palavra mais utilizada pelas mulheres em tempos de pandemia.

O espaço doméstico também tem estado candente num outro sentido: o confinamento em casa potenciou e aumentou as situações de violência doméstica contra mulheres e crianças, o que nos leva a questionar se o isolamento protege, como já o fizemos em estudo relativo à separação de vagões em metrôs para proteger as mulheres de potencial assédio (sexual; físico; moral), agressões, abusos e demais circunstâncias vexatórias e degradantes(ver: MIRANDA; YANNOULAS, 2017). Naquele estudo apontou-se que a separação de vagões tem se mostrado uma medida paliativa, a qual reproduz a culpabilização das usuárias do serviço de transporte público, além de gerar contínuas consequências ao público-alvo e demais usuários(as) que não se enquadrem na separação binária entre gêneros. No caso em pauta aqui, cabe que nos questionemos se o isolamento social protege ou apenas confina às mulheres, coletivamente, a que elas sofram em solidão pelas tarefas de cuidados, ao mesmo tempo em que precisam criar e reinventar vários avatares para que participem dos diversos trabalhos remotos (aulas, reuniões etc.), fingindo ignorar os estragos da violência doméstica, seja física ou simbólica, representando ou atuando um avatar eficiente, concentrado e eternamente disponível para os e as outras, através de uma tela de computador ou celular.

Nota Técnica publicada pelo Instituto de Pesquisa Econômica Aplicada (IPEA, 2020) chama a atenção para essa situação e demanda ações e políticas públicas para seu urgente enfrentamento. O Ipea, com base nos dados longitudinais da Pnad Contínua (IBGE, 2018), produzida pelo Instituto Brasileiro de Geografia e Estatística (IBGE), aponta que o desemprego na pandemia atingiu com mais força as trabalhadoras no Brasil: a participação das mulheres no mercado de trabalho é a menor em 30 anos (participação média das mulheres no mercado de trabalho entre abril e junho: $46 \%$ ), sendo a taxa de participação de mulheres com filhos a mais afetada (BARBOSA et. al, 2020).

No âmbito do espaço público, a divisão sexual do trabalho estabeleceu áreas e funções para a inserção diferenciada e desigual de homens e mulheres. A dupla segmentação (horizontal e vertical) restringe as áreas de atividade econômica disponíveis para as mulheres. E mesmo nas áreas nas quais o gênero feminino predomina, raramente são comandadas por mulheres (YANNOULAS, 2013). Em recente estudo sobre a inserção das mulheres no serviço público federal, entre 1998 e 2016, com base nas estatísticas oficiais disponíveis coletadas e sistematizadas especificamente para mostrar as "barreiras 
invisíveis" baseadas no gênero das(os) servidoras(es), pode ser observada nitidamente a inserção majoritariamente feminina nas áreas de cuidado (social; educacional; assistencial; saúde) da administração pública indireta, especialmente em âmbito municipal (XAVIER; YANNOULAS, 2019). As autoras apontam que houve um pequeno aumento na participação das mulheres na administração pública federal: em 1998, as mulheres representavam 43,9\% das(os) servidoras(es) públicas(os) federais e, 18 anos depois, 46,4\%. Este aumento esteve associado principalmente à contratação de professoras universitárias.

As pesquisadoras também destacam a desigual distribuição de homens e mulheres na administração pública federal direta, autárquica e fundacional: o Ministério da Educação, o Ministério da Saúde e o Ministério da Previdência Social concentram a maior parte das servidoras públicas federais, sem atingir, entretanto, cargos e funções de alto nível. Em 2016, a cada 1.000 mulheres empregadas na administração pública federal direta, autárquica e fundacional, 524 estavam no Ministério da Educação, 139 no Ministério da Saúde e 75 no Ministério da Previdência Social. A participação das mulheres era maior na administração pública indireta e menor na administração pública federal direta. A segregação horizontal no âmbito da administração pública federal não era apenas temática, mas também funcional. Os homens, mais do que as mulheres, atuavam na elaboração das políticas públicas e as mulheres, mais do que os homens, na sua implementação.

Análises sobre a feminização de diversos setores e atividades produtivos relacionados com o uso intensivo de tecnologia digital também podem ser importantes para compreender o atual momento de instauração massiva do trabalho não presencial (docente ou não). Constituem exemplos da divisão sexual do trabalho na configuração do capitalismo contemporâneo, intensificando e precarizando o trabalho feminino de maneira inédita. Por exemplo, as operadoras de telemarketing ou de caixa de supermercado, com exaustivo controle dos corpos, dos ritmos, dos tempos, da voz, das emoções e do comportamento, nos quais a tecnologia digital se apresenta como o principal mecanismo de extração do sobretrabalho, fator imprescindível para a acumulação do capital de maneira duplicada: pela intensificação do trabalho remunerado das mulheres e pela manutenção do trabalho doméstico realizado predominantemente por elas (YANNOULAS, 2013). No caso do trabalho docente remoto, acrescenta-se a precarização das condições de trabalho, envolvendo a utilização intensiva de equipamento, software, conectividade próprias das professoras, para o desenvolvimento das tarefas que lhes competem. Importante é considerar que, em texto ainda a ser homologado pelo Ministério de Educação, perante o estado de calamidade pública, o Conselho Nacional de Educação aprovou, no dia 6 de outubro de 2020, a manutenção do ensino remoto em instituições educacionais públicas e privadas, de educação básica e ensino superior, até dezembro de $2021^{8}$.

Há algum tempo, manifestamos nossa preocupação com a formulação de políticas para as mulheres e de gênero, no sentido de interpretar que aquelas para as mulheres normalmente estão dirigidas a resolver problemas práticos ou necessidades básicas de 
outras pessoas decorrentes da posição que as mulheres ocupam na sociedade e na divisão sexual do trabalho. E, por sua vez, as políticas de gênero são orientadas a desafiar a divisão sexual do trabalho cristalizada através dos tempos, com foco em interesses estratégicos feministas (YANNOULAS; SILVA, 2017). A necessidade de distinguir os interesses estratégicos das necessidades ficou mais evidente no atual contexto da pandemia. A luta pelos interesses estratégicos se manteve ativa e palpitante quanto aos direitos sexuais e reprodutivos, provocados pelas nefastas decisões em torno de casos de aborto permitidos por lei, conforme amplamente noticiado pela mídia ${ }^{9}$. Entretanto, no que diz respeito à divisão sexual do trabalho, as poucas políticas públicas implementadas, desde 2016, consolidaram ainda mais a função social das mulheres como cuidadoras, em defesa e atuação em prol dos cuidados com outrem.

Se já foi apontado um déficit de cuidado antes da pandemia (MARCONDES; YANNOULAS, 2012), este déficit foi agudizado devido à diminuição da corresponsabilização do Estado pela provisão social, desde 2016, sob a égide da ideologia do neoconservadorismo (que, paralelamente, preconiza a familiarização das políticas sociais e a progressiva limitação de recursos dos programas e ações estatais, comprometendo a já incipiente rede de equipamentos e serviços sociais), por meio de propostas de reformas da administração pública e diminuição dos investimentos públicos na área social, resultando no reforço da responsabilidade pelo cuidado para as famílias, principalmente para as mulheres.

\section{Trabalho docente e pandemia a partir dos estudos de gênero}

A pesquisa intitulada Trabalho docente em tempos de pandemia (GESTRADO, 2020b) foi realizada pelo Grupo de Estudos sobre Política Educacional e Trabalho Docente da Universidade Federal de Minas Gerais (Gestrado/UFMG), em parceria com a Confederação Nacional dos Trabalhadores em Educação (CNTE), nas etapas de mobilização dos respondentes em âmbito nacional e de divulgação dos resultados em âmbito nacional e internacional ${ }^{10}$. O Gestrado foi o responsável pelo desenho metodológico da pesquisa, construção do instrumento de coleta de dados, além da sistematização e da análise das respostas.

O grupo de pesquisa e a confederação, corajosamente e logo no início da crise sanitária, se dispuseram a desenvolver pesquisa específica sobre trabalho docente na educação básica durante a pandemia. Buscou-se conhecer os efeitos da pandemia da Covid-19, especificamente sobre o trabalho docente na educação básica pública nos estados, no Distrito Federal e municípios do Brasil. Neste artigo analisamos alguns dos achados da pesquisa desde o ponto de vista das relações de gêneros ${ }^{11}$.

As primeiras informações sobre as 15.654 docentes da educação básica das redes públicas que participaram do questionário foram referentes às características demográficas e à vinculação profissional. As mulheres representavam $78 \%$ dos respondentes, 
sendo que metade dos participantes era constituída por mulheres com idades entre 30 a 49 anos (Tabela 1).

Tabela 1: Característica demográfica docente: por faixa etária e por gênero

\begin{tabular}{l|l|l|l}
\hline Faixa etária & Feminino & Masculino & Total \\
\hline Até 29 anos & $5,5 \%$ & $2,3 \%$ & $7,8 \%$ \\
\hline De 30 a 39 anos & $20,6 \%$ & $6,6 \%$ & $27,3 \%$ \\
\hline De 40 a 49 anos & $30,2 \%$ & $7,0 \%$ & $37,2 \%$ \\
\hline De 50 a 59 anos & $19,0 \%$ & $4,7 \%$ & $23,7 \%$ \\
\hline 60 anos ou mais & $3,0 \%$ & $1,0 \%$ & $4,0 \%$ \\
\hline Total & $78,3 \%$ & $21,7 \%$ & $100,0 \%$ \\
\hline
\end{tabular}

Fonte: GESTRADO, 2020b.

Quanto à vinculação profissional, a maior parte das respondentes atuava nas redes públicas municipais e estaduais (Tabela 2).

Tabela 2: Vinculação profissional docente por gênero

\begin{tabular}{l|l|l}
\hline Rede de Ensino & Mulheres & Homens \\
\hline Municipal & $49,5 \%$ & $10,0 \%$ \\
\hline Estadual & $27,6 \%$ & $11,3 \%$ \\
\hline Federal & $0,9 \%$ & $0,3 \%$ \\
\hline Total & $78,1 \%$ & $21,6 \%$ \\
\hline
\end{tabular}

Fonte: Elaboração das autoras com base em GESTRADO, 2020a.

Quando questionadas(os) sobre suas experiências anteriores em aulas não presenciais, a maioria afirmou não possuir experiência anterior. Ou seja, o atual contexto pandêmico que demandou o intenso uso de ambientes virtuais para o ensino tem sido uma novidade para as(os) professoras(es), sendo que as mulheres participantes da pesquisa correspondiam a 90,1\% e os homens a $83,5 \%$ (Gráfico 1).

Gráfico 1: Experiência docente anterior ministrando aula não presencial, por gênero 


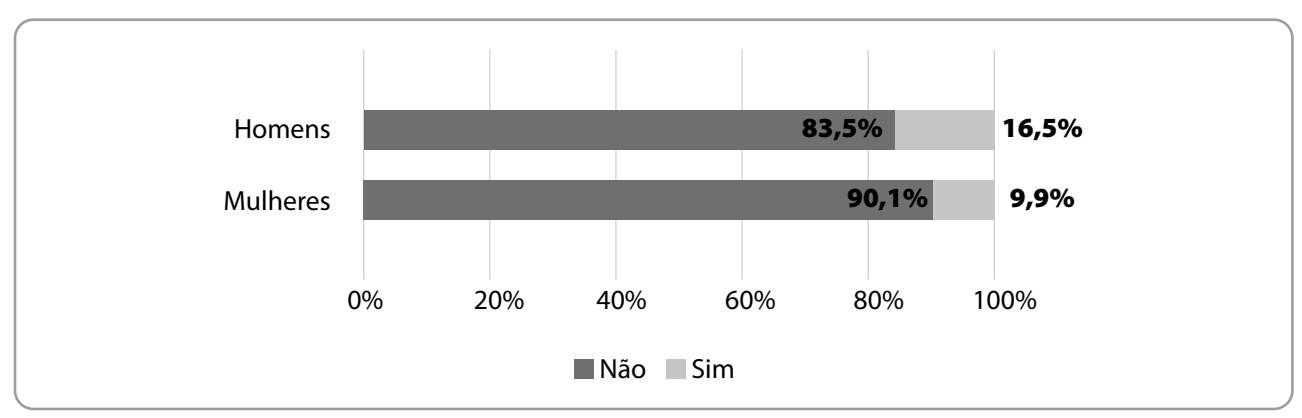

Fonte: Elaboração das autoras com em GESTRADO, 2020a.

O isolamento social impôs novas rotinas de trabalho docente. A oferta de ensino remoto, utilizando tecnologias digitais de informação e comunicação (TDIC), pouco usuais no trabalho presencial, tem sido um grande desafio para a maioria dos docentes. Quanto à familiaridade com tais tecnologias, as professoras respondentes consideram ser mais difícil o uso de ferramentas digitais que os homens. No Gráfico 2, entre os respondentes que consideram ser difícil ou muito difícil, as mulheres representaram a maioria (85\% e $85,6 \%$, respectivamente). Somente $28,9 \%$ dos respondentes afirmam possuir facilidade para o seu uso (GESTRADO, 2020: 9), embora não seja de hoje a demanda de inserção de atividades pedagógicas com uso de TDIC no contexto escolar. Como observamos no Gráfico 2, no caso das mulheres, 63\% consideraram muito fácil e 73\%, fácil. Os professores respondentes apresentaram dados inversos. A maior parte considera mais fácil o uso das TDIC, como percebemos no Gráfico 2.

\section{Gráfico 2: Domínio das tecnologias digitais pelos docentes, por gênero}

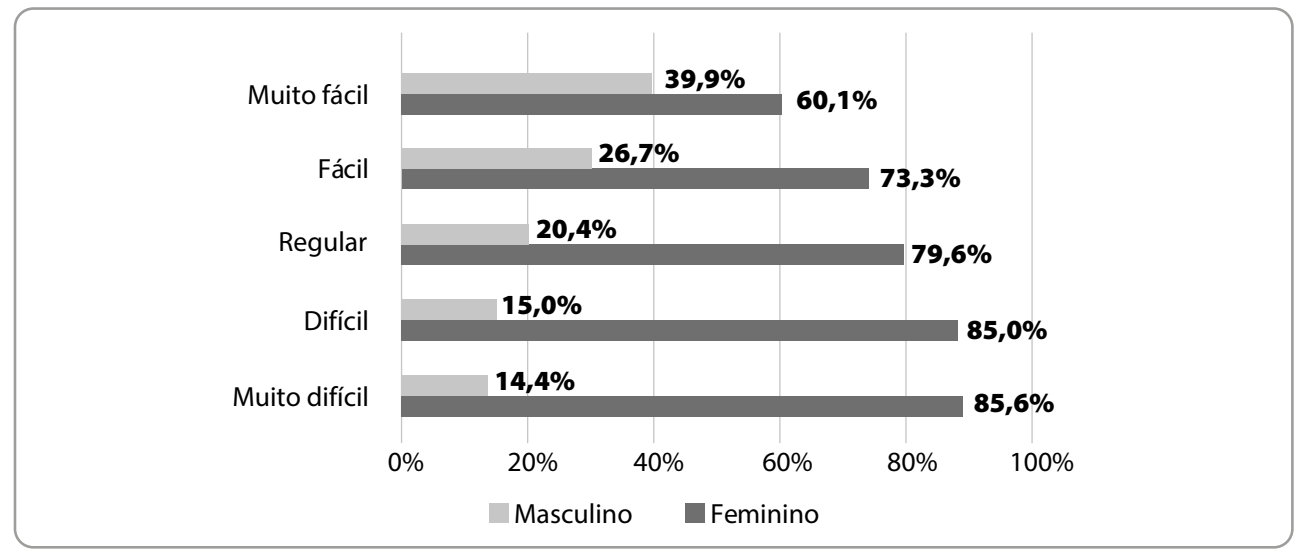

Fonte: Elaboração das autoras com base em GESTRADO, 2020a. 
A participação em atividades formativas para o uso de tecnologias digitais no contexto educacional apresentou relativo equilíbrio entre os gêneros (Gráfico 3). Embora os dados gerais demonstrem que a maioria das(os) profissionais não tenha recebido qualquer formação para o desenvolvimento das atividades, percebe-se que o compromisso das(os) professoras(es) com seus estudantes tem orientado a busca de meios para tornar a oferta educativa possível (GESTRADO, 2020).

\section{Gráfico 3: Participação docente em formação para uso de tecnologias educacionais digitais, por gênero}

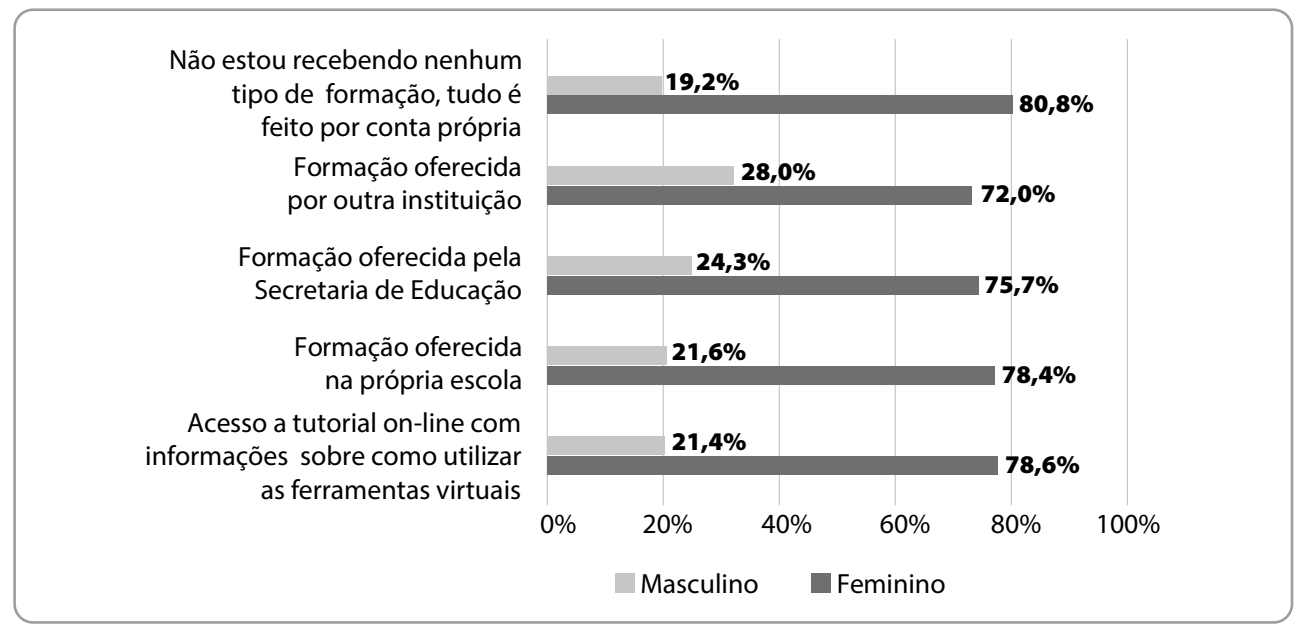

Fonte: Elaboração das autoras com base em GESTRADO, 2020a.

No geral, 83\% possuem recursos próprios, em casa, para ministrar aulas não presenciais. Quando analisamos os dados desagregados por gênero, percebe-se que havia um certo equilíbrio entre mulheres e homens que possuíam tais recursos em casa (Gráfico 4). Porém, a metade compartilhava os recursos digitais (como computadores, notebooks, smartphones, tablets) com outras pessoas no domicílio e apenas metade dos respondentes fazia uso exclusivo dos recursos tecnológicos (GESTRADO,2020b). Os Gráficos 4 e 5 nos ajudam a compreender o diferencial de gênero sobre esta questão.

\section{Gráfico 4: Recursos dos docentes, em casa, para ministrar aulas não presenciais (remotas), por gênero}




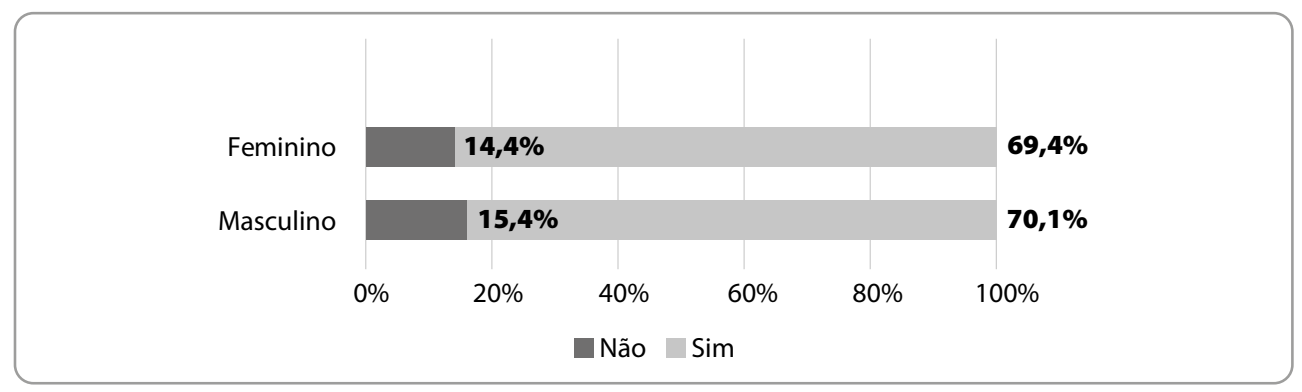

Fonte: Elaboração das autoras com base em GESTRADO, 2020a.

As respondentes compartilhavam mais seus equipamentos que os professores respondentes. Enquanto 52,6\% das professoras eram demandadas a compartilhar seus recursos digitais com outros membros da casa e, por isso, tinham o tempo de uso mais limitado, 45\% dos homens vivenciavam esta situação. E, ainda, 47,1\% das mulheres utilizavam seus equipamentos exclusivamente e $54,6 \%$ dos homens estavam nesta condição.

\section{Gráfico 5: Compartilhamento de recursos digitais pelos docentes, por gênero}

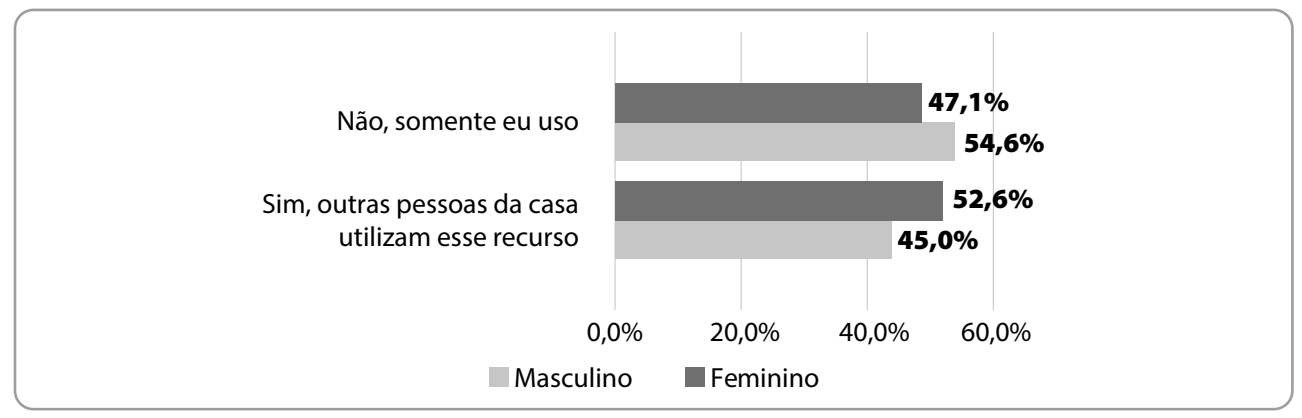

Fonte: Elaboração das autoras com base em GESTRADO, 2020a.

Em relação à dedicação de horas de trabalho para a preparação das aulas não presenciais, a percepção da maioria dos respondentes foi de que houve um aumento nas horas de trabalho gastas na preparação das aulas não presenciais, o que de fato ocorreu para a grande maioria em todas as etapas da educação básica (GESTRADO, 2020b). O Gráfico 6 permite observar as variações de gênero sobre horas de trabalho.

Em relação ao gênero, a maior parte das mulheres (e dos homens) teve a percepção de aumento das horas de trabalho. Porém, interessante perceber que comparativamente, mais mulheres (83,3\%) possuíam tal percepção que os homens (79,6\%). Em relação à diminuição das horas de trabalho para preparação de aulas não presenciais, mais homens (6,5\%) possuíam tal percepção que mulheres $(4,9 \%)$. 
Gráfico 6: Dedicação docente para preparação das aulas não presenciais em comparação à preparação das aulas presenciais, por gênero

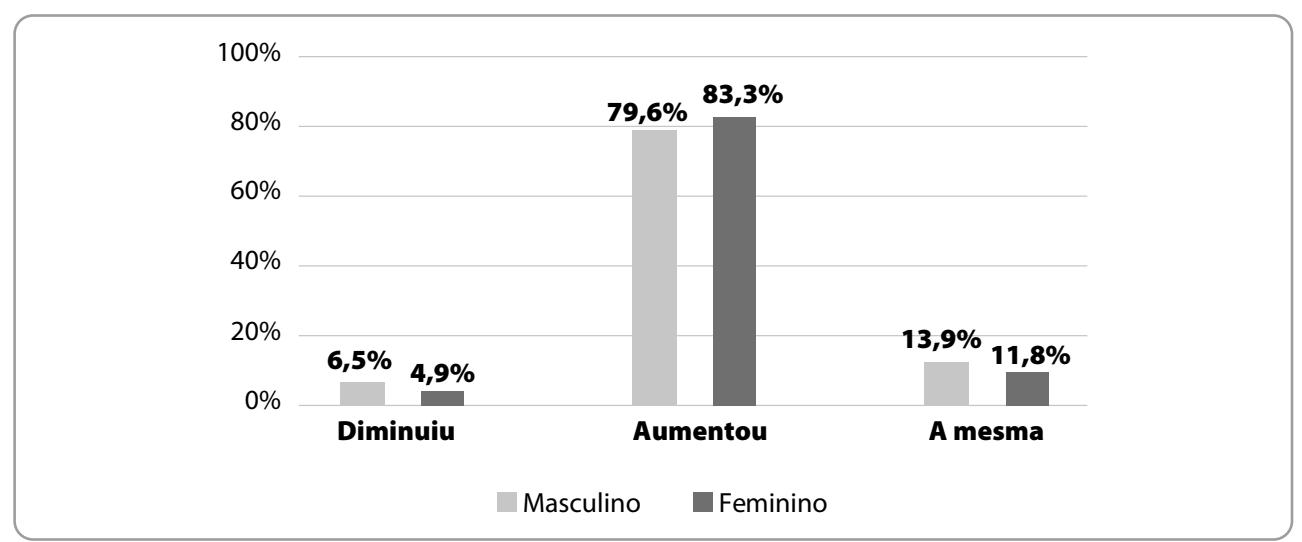

Fonte: Elaboração das autoras com base em GESTRADO, 2020a.

A questão da subjetividade e dos sentimentos também foi contemplada na pesquisa. Quando solicitadas(os) a que descrevessem seu sentimento em relação ao seu trabalho neste momento, as(os) respondentes apontaram nas respostas angústia, apreensão, medo e insegurança, solidão e tranquilidade. Conforme indicado no Gráfico 7, as mulheres demonstraram ter mais medo e insegurança por elas não saberem quando e como será o retorno à normalidade (80,2\%) e mais angústia em relação ao futuro. Os homens mencionaram que se sentiam mais apreensivos em relação à perda de direitos e garantias (25,5\%), mas com maior tranquilidade por eles saberem que logo a normalidade seria retomada.

\section{Gráfico 7: Sentimento docente em relação ao trabalho neste momento de pandemia, por gênero}

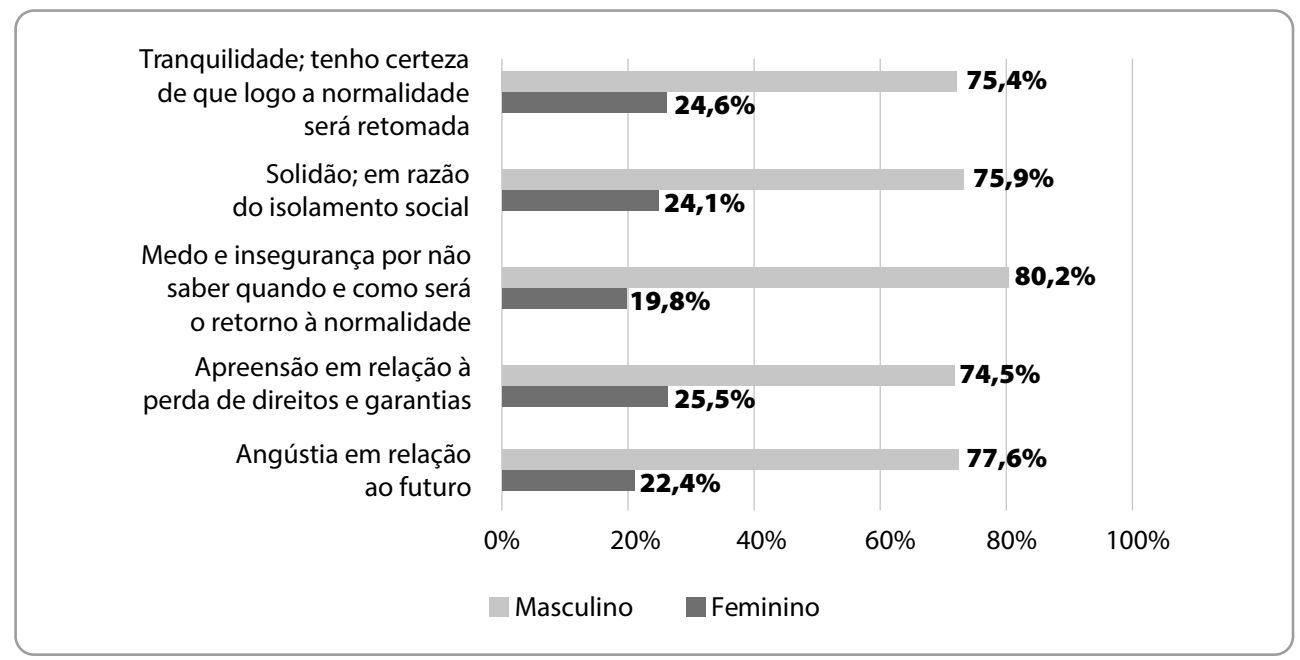

Fonte: Elaboração das autoras com base em GESTRADO, 2020a. 
Fato que merece destaque é o suporte emocional e psicológico fornecido por parte das instituições ao corpo docente neste período pandêmico e com excessivas demandas laborais. A maioria das(os) respondentes (63,4\%) afirmou que não vem recebendo tal suporte emocional ou psicológico. Em relação aos gêneros, contudo e conforme gráfico a seguir, percentualmente mais mulheres (37,9\%) que homens (32,1\%) disseram que estariam recebendo tal suporte emocional e psicológico.

\section{Gráfico 8: Suporte emocional e psicológico da escola aos docentes, por gênero}

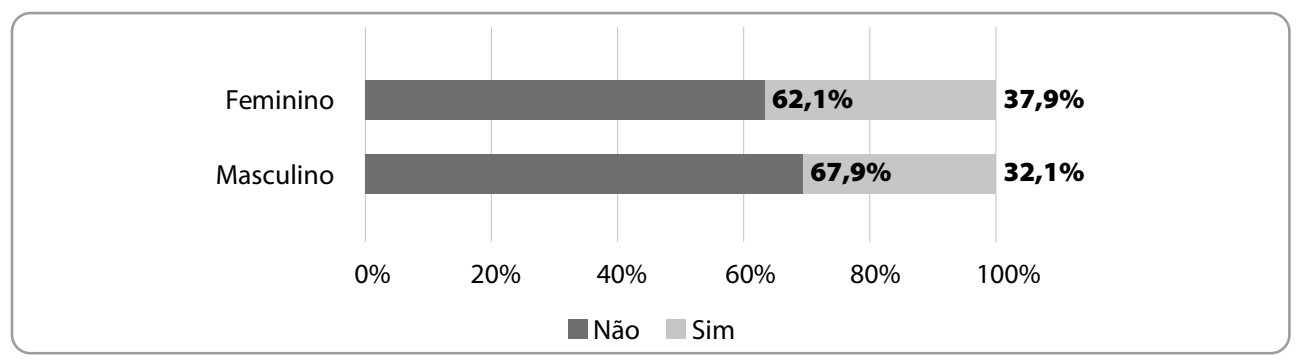

Fonte: Elaboração das autoras com base em GESTRADO, 2020a.

Enfim, cabe ressaltar que tais dados contribuem para o melhor conhecimento da complexidade da realidade atual do trabalho docente na educação básica, no que diz respeito ao enfrentamento de situações impostas pela pandemia e a oferta de pública de qualidade socialmente referenciada. A situação é completamente nova e inesperada, ou seja, ninguém estava preparado para enfrentar os desafios que a pandemia impõe. E esta situação agudiza a desigualdade social de classe, gênero e raça estruturante pré-existente na realidade educacional brasileira.

\section{Ser professora na/da pandemia}

A questão docente é complexa e, por isto mesmo, precisa ser analisada de forma contextualizada e referenciada teoricamente. Cabe lembrar que o trabalho docente não se refere apenas à sala de aula ou ao processo de ensino formal, pois compreende a atenção e o cuidado, além de outras atividades inerentes à educação formal (OLIVEIRA, 2010).

A partir dos dados de pesquisa apresentados, discutimos algumas questões relevantes. Uma delas diz respeito às condições de trabalho docente na educação básica. Concordamos com Oliveira (2010) que a relevância em se discutir o tema está baseada no conhecimento dos efeitos nas condições em que os trabalhadores exercem suas atividades, sobre eles próprios e sobre os resultados almejados. 
Neste sentido, a intensificação e também a autointensificação têm sido percebidas, no atual contexto pandêmico, no qual as professoras vêm sendo responsabilizadas pelo processo educativo e pelo desempenho dos alunos, da escola e do sistema educacional (OLIVEIRA, 2020). As professoras estão assumindo novas funções e responsabilidades, principalmente aquelas ligadas à produção de recursos digitais, a fim de responder às exigências da comunidade escolar na qual estão inseridas. Também é cobrado delas a não reprovação das(os) estudantes, sem por isso diminuir a qualidade.

No contexto da escola pública, é importante lembrar que a maioria das professoras assumem mais de uma jornada de trabalho em diferentes escolas. E em contexto de isolamento social, em casa, as professoras assumem, além das atividades pedagógicas do trabalho docente remunerado, as atividades domésticas de cuidado que garantem as condições materiais para atender (ou "dar conta") às (das) necessidades básicas dos seres humanos, especialmente crianças, idosos e pessoas com deficiência. E o cuidado na pandemia aumentou, revelando que o feminino, enquanto construção social e histórica, ancora-se na divisão sexual do trabalho, articulada às desigualdades de classe e raça (MARCONDES; FARAH, 2020).

Outra questão importante se refere à utilização das TDIC nas atividades pedagógicas. Diante das variadas funções que a escola pública assume na atualidade, as professoras se veem muitas vezes obrigadas a responder a exigências para as quais não se encontram preparadas (OLIVEIRA, 2010). A utilização das TDIC em sala de aula e o seu domínio por parte das professoras não constitui totalmente uma novidade, bem como as dificuldades de acompanhar a inserção desses recursos nas atividades pedagógicas. Arruda (2020) considera que a situação emergencial é também momento propício para fomentar uma política de universalização do acesso às informações e conhecimentos disponibilizados pela internet. Contudo, o autor considera que, no quadro atual de desenvolvimento tecnológico, "estamos dentro de possibilidades de reconfigurar as políticas de acesso tecnológico não mais ao acesso institucional (por meio da escola), mas a um acesso individual, em que todos as pessoas vinculadas à escola têm direito a esse bem" (p. 272).

A mudança acelerada do contexto social coloca, a cada dia, novas exigências à docência. O mal-estar docente, como afirma Martinez (2010), se expressa no campo da subjetividade, categoria que permite rastrear o processo no nível do singular e como fenômeno coletivo. Permite desvelar representações, valores e atitudes que se constroem num marco de possibilidades que é sempre histórico.

Mancebo (2010) nos ajuda a compreender toda a nova organização do trabalho, pois a flexibilização constrói-se acompanhada de um movimento de reacomodação do campo sócio-subjetivo, produz novas performances para a força de trabalho docente que vêm afetando sua organização, sua dinâmica interpessoal, além de exigir-lhe uma ativa adaptação espaço-temporal. 
Assim, do mesmo modo como assistimos aos novos contornos que se desenham para o capitalismo nas sociedades contemporâneas, a uma produção maleável e individualizada, à valorização dos trabalhadores qualificados polivalentes, à flexibilização da organização do trabalho, à implementação de horários indefinidos de trabalho e à precarização dos vínculos trabalhistas, também presenciamos a convocação irrestrita da subjetividade do trabalhador para o centro dos processos de trabalho, não raramente com aumento do sofrimento subjetivo, neutralização da mobilização coletiva e aprofundamento do individualismo (MANCEBO, 2010, p.3).

Para a autora, a subjetividade deve ser abordada como totalidade, compreendendo, como ensina a abordagem sócio-histórica, "um conjunto de fenômenos relacionados e em processo, produzidos subjetivamente na relação com a objetividade, que é material e social" (p.1).

Tal perspectiva nos auxilia na compreensão dos resultados da pesquisa quanto às vivências das professoras de educação básica respondentes, na atual conjuntura pandêmica mundial. As mulheres, como demostrado até aqui, têm abraçado, de maneira audaciosa e praticamente sem rede de proteção, um contexto de mudanças objetivas e subjetivas. E não diferentemente das demais profissões femininas, as professoras também.

\section{De operárias do giz a operárias do clique}

Ao longo do texto, buscamos discutir a relação entre o trabalho docente na educação básica, a feminização e a pandemia. A pesquisa, realizada pelo Gestrado, com apoio da CNTE, demonstrou, a profunda agudização dos problemas de gênero imperantes no trabalho docente na educação básica, problemas estes cristalizados antes mesmo da instauração da pandemia.

O aumento das tarefas, a instalação de horários atípicos, a aceleração no desempenho das atividades, a dimensão privada sendo desvelada pelas TDIC e a ausência de condições materiais efetivas afetaram em cheio a produção docente e sua subjetividade, tendo como principal alvo as professoras no exercício de suas funções docentes, maternais, de cuidadoras, entre outros "avatares" que precisam utilizar na múltipla jornada de trabalho, e uma "presença" cada vez mais multiplicada.

Todavia, esperançamos com Mancebo (2010), que afirma ser necessário considerar que a rede de relações e produções que se constitui no âmbito escolar também pode caminhar na contramão do ajustamento à ordem social e da alienação, "com sujeitos agindo coletivamente em busca de brechas e possibilidades de escape na direção da crítica ao prescrito, na busca de crescimento subjetivo, de mais-prazer e solidariedade" (p.4). Neste sentido, nossos votos são pela construção de uma nova divisão sexual do trabalho, de uma nova escola e de um novo trabalho docente, mais valorizado e justo socialmente, que consigam surgir do esgotamento do modelo atualmente tensionado pela pandemia. 
Recebido em: 16/10/2020 e Aprovado em: 10/11/2020

\section{Notas}

1 Dentre elas, escolas (confessionais; estaduais; federais; municipais; particulares) da educação infantil ao ensino superior, creches e outras. Com a pandemia, medidas sanitárias foram tomadas em todos os âmbitos, atingindo o cotidiano das pessoas, em especial, quanto à restrição de circulação.

2 Segundo dados do Censo Escolar de 2019, do Instituto Nacional de Estudos e Pesquisas Educacionais Anísio Teixeira (Inep), o Brasil tem 47,9 milhões de estudantes na educação básica e 8,4 milhões no ensino superior, portanto, há uma população de 56,3 milhões de estudantes fora das salas de aula, desde março de 2020 (Fonte: BRASIL/MEC/CNE, 2020).

3 Neste texto optamos por usar o gênero gramatical feminino para fazer referência às categorias profissionais predominantemente femininas, como: professora, pedagoga, assistente social, psicóloga, entre outras.

4 Cerca de 2,2 milhões de docentes atuam na educação básica e 384.474 docentes no ensino superior (Fonte: BRASIL/MEC/CNE, 2020).

5 O conceito de "doble presencia" (dupla presença) foi utilizado pela primeira vez em 1978, pela socióloga italiana Laura Balbo. A dupla presença significa grande dificuldade enfrentada pelas mulheres, pois são responsabilizadas duplamente: na família e no trabalho. Implica a dupla ausência também, pois provoca a sensação de estarem sempre em dívida com os dois ambientes (familiar e laboral), conduzindo ao estresse e outras doenças (ver Introdução em Yannoulas; 2013). Hoje poderíamos falar de "múltipla presença", intensificada e ampliada, que ao mesmo tempo demanda atenção em vários ambientes presenciais e virtuais e sobrecarrega ainda mais às mulheres, aumentando paralelamente a margem de lucro do capitalismo.

6 Marcondes e Farah (2020) discutem a questão do cuidado na pandemia e consideram que, apesar do termo cuidado ser bastante presente no nosso cotidiano, ainda há pouca reflexão sobre esta prática social e sobre seus significados. Em uma abordagem feminista, as autoras consideram que o cuidado se combina a três dimensões: trabalho, emoções e ética.

7 Verificar em: <https://www.bbc.com/portuguese/geral-51842518>. Acesso em: 15 out. 2020.

8 Pelo parágrafo único do primeiro artigo da Lei 14.040, de 18 agosto de 2020 (BRASIL, 2020b), o CNE excepcionalmente editará diretrizes para a educação durante o contexto de pandemia <http://www.planalto.gov. br/ccivil_03/_ato2019-2022/2020/lei/L14040.htm>. Acesso em: 15 out. 2020.

9 Dias depois do aborto realizado legalmente em uma criança de 10 anos que foi estuprada no Espírito Santo virar campo de batalha no Brasil, o Ministério da Saúde emitiu uma portaria alterando os procedimentos obrigatórios no atendimento médico para vítimas de estupro que desejam fazer um aborto. BBC NEWS BRASIL. Novas regras do governo sobre aborto após estupro "empurram" mulheres para abortamento ilegal, diz psicóloga. Disponível em: <https://www.bbc.com/portuguese/brasil-53965928>. Postado em:31 ago. 2020. Acesso em: 15 out. 2020.

10 Para mais informações, ver canal do Gestrado/UFMG no YouTube: $<$ https://www.youtube.com/user/GestradoUFMG>

11 Agradecemos a Henrique Cançado, Bacharel e Licenciado em Ciências Sociais pela Universidade Federal de Minas Gerais, o processamento dos dados da pesquisa do Gestrado (2020a), segundo recorte de gênero.

\section{Referências}


ARRUDA, Eucidio Pimenta. Educação remota emergencial: elementos para políticas públicas na educação brasileira em tempos de Covid-19. Em Rede, Porto Alegre, v. 7, n. 1, p. 257-275, 2020.

BARBOSA, Ana L. N. de H.; COSTA, Joana S.; HEKCSCHER, Marcos. Mercado de trabalho e pandemia da Covid-19: ampliação de desigualdades já existentes? Nota Técnica 69. Brasília: IPEA, julho de 2020. Disponível em: <http://repositorio.ipea.gov.br/handle/11058/10186>. Acesso em: 15 out. 2020.

BBC NEWS BRASIL. Coronavírus: OMS declara pandemia. Disponível em: <https://www.bbc.com/ portuguese/geral-51842518>. Postado em: 11 mar. 2020. Acesso em: 15 out. 2020.

BBC NEWS BRASIL. Novas regras do governo sobre aborto após estupro "empurram" mulheres para abortamento ilegal, diz psicóloga. Disponível em: <https://www.bbc.com/portuguese/brasil-53965928>. Postado em: 31 ago. 2020. Acesso em: 15 out. 2020.

BRASIL. Constituição da República Federativa do Brasil de 1988. Diário Oficial da União, de 05 de outubro. Brasília, 1988.

BRASIL. MEC, CNE. Parecer CNE/CEP 11/2020, Orientações educacionais para a realização de aulas e atividades pedagógicas presenciais e não presenciais no contexto da pandemia. Diário Oficial da União. de 3 de agosto, Seção 1, p. 57. Brasília, 2020a.

BRASIL. Lei 14.040, de 18 agosto de 2020. Estabelece normas educacionais excepcionais a serem adotadas durante o estado de calamidade pública reconhecido pelo Decreto Legislativo no ${ }^{\circ}$, de 20 de março de 2020; e altera a Lei nำ11.947, de 16 de junho de 2009. Diário Oficial da União, 18 de agosto de 2020. Brasília, $2020 \mathrm{~b}$.

GESTRADO. Base de dados: trabalho docente em tempos de pandemia. Belo Horizonte: UFMG, 2020a.

GESTRADO. Trabalho docente em tempos de pandemia: relatório técnico. Belo Horizonte: UFMG, 2020b.

IBGE. Pesquisa Nacional por Amostra de Domicílios Contínua. Notas técnicas - Versão 1.5. Rio de Janeiro: IBGE, 2018.

IPEA/DISOC. Políticas públicas e violência baseada no gênero durante a pandemia da Covid-19: ações presentes, ausentes e recomendadas. Nota Técnica 78. Brasília: jun. 2020.

MANCEBO, Deise. Subjetividade docente. In: OLIVEIRA, Dalila A; DUARTE, Adriana M. C. VIEIRA; Lívia M. F. Dicionário: trabalho, profissão e condição docente. Belo Horizonte: UFMG/Faculdade de Educação, 2010.

MARCONDES, Mariana M.; YANNOULAS, Silvia C. Práticas sociais de cuidado e a responsabilidade do Estado. Revista Ártemis, Brasília, v. 13, n.1, p.174 - 186, jan.jul. 2012.

MARCONDES, Mariana M; FARAH, Marta F. S. Cuidado nos tempos de pandemia. Blog do Estadão, 2020. Disponível em: https://politica.estadao.com.br/blogs/gestao-politica-e-sociedade/cuidado-nos-tempos-depandemia/. Acesso em 07 out. 2020.

MARTINEZ, Deolídia. Mal estar docente. In: OLIVEIRA, Dalila A; DUARTE, Adriana M. C. VIEIRA; Lívia M. F. Dicionário: trabalho, profissão e condição docente. Belo Horizonte: UFMG/Faculdade de Educação, 2010.

MIRANDA, Marina C; YANNOULAS, Silvia C. Vagões para mulheres: uma separação que protege? Cuestión Urbana, v. 2, n. 2, p. 29 - 42, 2017.

OLIVEIRA, Dalila A. Trabalho docente. OLIVEIRA, Dalila A; DUARTE, Adriana M. C. VIEIRA; Lívia M. F. Dicionário: trabalho, profissão e condição docente. Belo Horizonte: UFMG/Faculdade de Educação, 2010. 
SEMPREVIVA ORGANIZAÇÃO FEMINISTA; ORGANIZAÇÃO FEMINISTA GÊNERO E NÚMERO. Sem Parar. O trabalho e a vida das mulheres na pandemia. Relatório Completo, julho de 2020. Disponível em: $<\mathrm{http}: / /$ mulheresnapandemia.sof.org.br/relatorio/>. Acesso em: 18 set. de 2020.

XAVIER, Elaine M; YANNOULAS, Silvia Cristina. Os Tetos e as Paredes de Vidro da Administração Pública Federal Brasileira (1995 - 2017). Revista da Abet, [online], v.18, n. 2, p. 276 - 299, 2019.

YANNOULAS, Silvia Cristina (Coord.). Trabalhadoras: análise da feminização das profissões e ocupações. Brasília: Editorial Abaré, 2013.

YANNOULAS, Silvia Cristina; SILVA, Ismália A. Necessidades Práticas das Mulheres $x$ Interesses Estratégicos Feministas. Revista Feminismos, v. 5, n. 2 e 3, p. 25-39, 2017. 